\title{
Chemical Composition of Mentha spicata L. subsp. tomentosa and M. pulegium L., and their Antimicrobial Activity on Strong Pathogen Microorganisms
}

\author{
Emre SEVINDİK*, Çiğdem YAMANER, \\ Cemal KURTOĞLU, Betül TIN
}

\author{
Adnan Menderes University, Faculty of Agriculture, Department of Agricultural Biotechnology, South Campus, Cakmar-Aydin, \\ Turkey;ph.d-emre@hotmail.com (correspondingauthor*)
}

\begin{abstract}
Mentha L., recognized as a medical and aromatic plant, is a general name affiliated to mint species and belongs to Labiatae family. Some species are used as fresh vegetables in the Turkish kitchen and they can also be used in salads. In addition, some species have been used as a spice in food. In this study, chemical composition and antimicrobial activity towards some pathogenics (gram + and gram -) microorganisms of the essential oils Mentha spicata L. subsp. tomentosa (Briq.) Harley, Mentha pulegium L. grown under West Anatolian ecological conditions were investigated. Extractions were carried out with Clevenger apparatus and essential oil composition was determined by Gas Chromatography-Mass Spectrometry (GC-MS). Microorganisms used for the antimicrobial studies were Methicillin-resistant Staphylococcus aureus (MRSA), Staphylococcus aureus ATCC 6538, Pseudomonas aeruginosa, Enterococcus faecium DSM 13590, Escherichia coli Q157:H7 and Bacillus cereus CCM99. As a result, M. pulegium and M. spicata subsp. tomentosa were found to be rich in piperitenone oxide: $72.77 \%$ and $25.84 \%$, respectively. Each of the oils was found to possess antimicrobial properties against test microorganisms. Essential oils obtained from Mentha species give positive effect on all microorganisms.
\end{abstract}

Keywords: Mentha, essential oils, GC-MS, antimicrobial, Turkey

\section{Introduction}

Since ancient times, the crude herbal extracts of aromatic plants have been in use for different purposes such as food, perfumery, and drugs. The medicinal properties of these plants have been investigated in the recent scientific developments (Ekren et al., 2013). Recently, there has been considerable interest in essential oils and extracts of medicinal and edible plants, herbs, and spices for the development of alternative food additives, in order to prevent the growth of foodborne pathogens or to delay the onset of food spoilage (Çetin et al., 2011). Labiatae family, spreading on a large area in the world, consists of 236 genus and 7133 species. Labiatae exists especially in tropical and mild regions like Mediterranean region, on tropical high plains having seasonal climate (Yllar $e t$ al., 2015). Mentha L., recognized as a medical and aromatic plant, is a general name affiliated to mint species and belongs to Labiatae family. This plant is represented by 62 taxon in the world and 15 taxon in Turkey (Başer et al., 2012). Some members of this genus are also used as herbal teas and condiments both in fresh and dried form due to their distinct aroma (Başer et al., 1999). Mentha is a plant of economic importance, distributed over a wide area in the world. Some species are used as vegetables in the Turkish kitchen and in salads. In addition, some species have been used as a spice in food (Deniz et al., 2010).

The aim of the present study was to determine the essential oil contents of Mentha spicata subsp. tomentosa, and Mentha pulegium growing under West Anatolian ecological conditions and to investigate their antimicrobial effect on various bacteria.

\section{Materials and Methods}

\section{Plantmaterial}

M. spicata subsp. tomentosa and M. pulegium aerial parts of the plants were collected in July 2015, which is their blooming period in Aydin and its surroundings (Fig. 1). The collected samples were placed in fabric bags and kept in a room with no sunlight. 


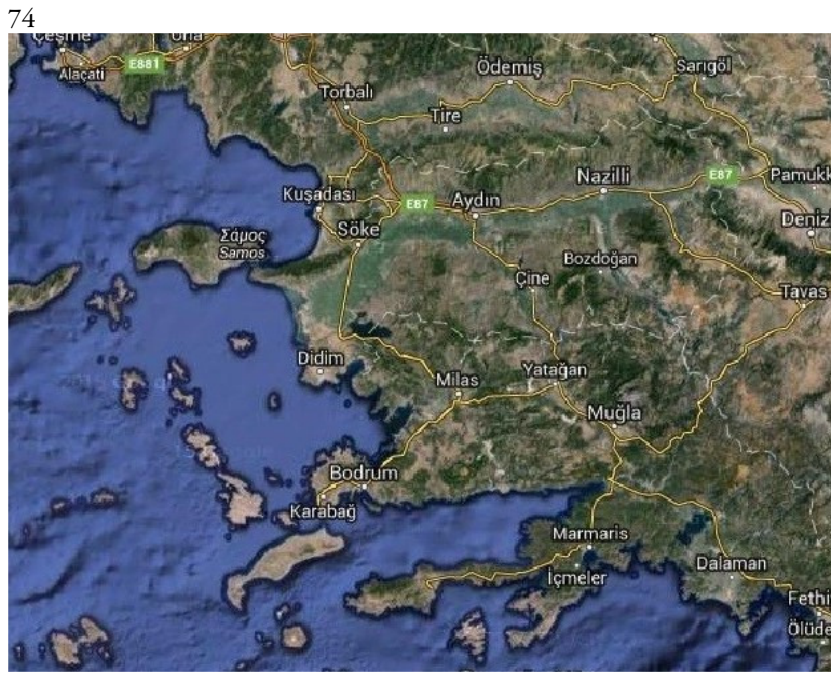

Fig. 1. Location of the Aydin region. Map data: US Dept of State Geographer 2015 Google 2015 Basarsoft Image Landsat

\section{Isolation of essential oils}

Approximately $150 \mathrm{~g}$ of plant samples were used for the essential oil extraction process. Extraction was performed with Clevenger apparatus (Basaran glass, Turkey and Misung Scientific Co., Korea) using water distillation.

\section{$G C-M S$ analysis}

Qualitative and quantitative essential oil analysis were conducted at Eskisehir Anadolu University Medicinal Plants, Drugs and Scientific Research Center (AUBIBAMM) by Hewlett Packard 5973 Mass Selective Detector System and GC-MS 6890 instrument equippped withan Agilent HPInnowax colon (60m X $0.25 \mathrm{~mm}$ film, $0.25 \mu \mathrm{m}$ thickness). Hellium was used as a carrier gas. Conditions were as follows; from $50^{\circ} \mathrm{C}$ to $240^{\circ} \mathrm{C}$ by an increase of $4^{\circ} \mathrm{C} /$ minutes. At 240 ${ }^{\circ} \mathrm{C}$, 40 minutes of waiting time were implemented. Injection port and detector temperature were $240{ }^{\circ} \mathrm{C}$ and $280{ }^{\circ} \mathrm{C}$ respectively. Chracterization of essential oil components was based on the library (Wiley and NIST) comparison with the mass spectra of the injected essential oil samples.

\section{Preparation of microorganism cultures}

Antimicrobial activity of the plants extracts was detected by four different gram positive (Methicillin-resistant Staphylococcus aureus (MRSA), Staphylococcus aureus ATCC 6538, Enterecoccus faecium DSM 13590, Bacillus cereus CCM99) and two different gram negative (Pseudomonas aeruginosa, Escherichia coli Q157:H7) microorganisms using disc diffusion method. Stock bacterial cultures in Brain Heart Infusion Broth incubated at $37{ }^{\circ} \mathrm{C}$ for 24 hours. Microorganisms were adjusted to Mc Farland 0.5 density with sterile physiological water. Each microorganism was planted into petri dishes containing Muller Hinton Agar with expansion method. Then, the petri dishes were allowed to dry at room temperature for 20-25 minutes. Afterwards, for the disc diffusion method, each disk was impregnated with $10 \mu \mathrm{L}$ of oil and allowed to incubate at $37^{\circ} \mathrm{C}$ for 24 hours. At the end of the incubation period, inhibition zones were measured from the lower surface of the petri dish. Tobramycin antibiotic was used as a control in all experiments. All trials were performed with two repetitions.

\section{Results}

\section{Chemical composition of the essential oils}

Essential oils are liquid, volatile, and rich in phenolic compounds (Santos et al., 2016). They are produced by the plants' secondary metabolism and are complex mixtures of low molecular weight terpenes. Their environmental function is related to defense against phytophagous insects and/or attraction of pollinators, as well as to intra- or inter-specific allelopathic phenomena (Tommasi et al., 2009). In this study, the chemical composition of M. spicata subsp. tomentosa and M. pulegium were given in Table 1.In total, 90 component ewere detected as M. spicata subsp. tomentosa aerial parts essential oil composition. $90.35 \%$ of the total essential oils in 20 components (components which are $\geq 0.4 \%$ in total ratio). The essential oils obtained from the M. spicata subsp. tomentosa plant were detected to contain piperitenone oxide $(25.84 \%)$, pulegone $(24.72 \%)$, cis piperitenone oxide (12.55\%) at most. In a recent revision, this taxon was given as a synonym of Mentha spicata subsp. condensata (Briq.) Greuter \& Burdet (Tucker and Naczi, 2007).

Mentha pulegium spreads on almost every place in the world, except for tropical regions. Topsoil parts of this plant are used for a traditional food or medical purposes as a guaiacol and against cholera, tuberculosis and poisoning (Tanker and Sezik, 1965; Yasa et al., 2012). In our study, a total of 76 components were detected as $M$. pulegium aerial parts essential oil composition. $93.22 \%$ of the total essential oils in 18 components (components which are $\geq 0.4 \%$ in total ratio) were given in Table 1 . The essential oils obtained from the $M$. pulegium plant were detected to contain piperitenone oxide (72.77\%), carvacrol (4.03\%), germacrene-D (3.79\%) at most. In past studies obtained from findings, our results have been determined to be proportionally different (Stoyanova et al., 2005; Mkaddem et al., 2007; Chalchat et al., 2000; MortezaSemnani et al., 2011; Yasa et al., 2012).

In general, these findings confirmed that the essential oil composition of the plants can have different quality and quantity in different geographical and environmental conditions, and during different periods of the plant growth (Mazandarani et al., 2013; Dastjerdi and Mazoji, 2015; Sevindik et al., 2016).

\section{Antimicrobial activity of the essential oils}

The most commonly studies of essential oils is related to antimicrobial activities. These oils have different antimicrobial effects on a variety of microorganisms including gram $(-)$ and gram (+) bacteria. As the essential oils are complex mixtures comprising different components, action levels thereof vary depending on diversity and amount of active substances. Despite having limited information relating to their mechanisms of action, this seems to be associated with lipophilic features and chemical structures of the oils (Bayaz, 2014). In this study, the disc diffusion method was used for determination of the in vitro antimicrobial activity of essential oils. The trials were performed with two repetitions and the average values are given in Table 2 .

The essential oil obtained from $M$. pulegium plant was effective against MRSA, E. faecium DSM 13590, S. aureus ATCC 6538, P. aeruginosa, E. coli $\mathrm{Q} 157: \mathrm{H} 7$ and B. cereus 
Table 1. Essential oil composition of M. spicata subsp. tomentosa and M. pulegium

\begin{tabular}{|c|c|c|c|c|c|}
\hline \multicolumn{3}{|c|}{ M. spicata subsp. tomentosa } & \multicolumn{3}{|c|}{ M. pulegium } \\
\hline RT & Component & Percent $(\%)$ & RT & Component & Percent $(\%)$ \\
\hline 11.55 & $\alpha$-pinene & 0.79 & 11.55 & $\alpha$-pinene & 0.56 \\
\hline 15.95 & $\beta$-pinene & 1.03 & 15.96 & $\beta$-pinene & 0.74 \\
\hline 16.71 & sabinene & 0.51 & 16.72 & sabinene & 0.40 \\
\hline 19.04 & $\beta$-myrcene & 0.59 & 19.06 & $\beta$-myrcene & 0.63 \\
\hline 20.77 & limonene & 1.59 & 20.79 & limonene & 1.82 \\
\hline 21.14 & 1,8-cineole & 1.72 & 37.32 & terpinen-4-ol & 0.40 \\
\hline 29.34 & 3-octanol & 0.59 & 39.07 & pulegone & 0.79 \\
\hline 33.25 & menthofuran & 1.78 & 39.83 & epibicyclosesquiphellandrene & 0.65 \\
\hline 36.58 & isopulegone & 0.51 & 41.09 & germacrene D & 3.79 \\
\hline 37.42 & caryophyllene & 1.38 & 45.05 & p-cymen-8-ol & 0.63 \\
\hline 39.34 & pulegone & 24.72 & 45.21 & 3,5-dimethylcyclohexen-1-one & 0.71 \\
\hline 41.34 & cis piperitone oxide & 12.55 & 45.77 & (1'-butenyl)thiophene & 0.47 \\
\hline 41.61 & 2-cyclohexen-1-ol & 0.88 & 48.02 & piperitenone oxide & 72.77 \\
\hline 41.83 & piperitone & 6.08 & 49.25 & benzene & 1.69 \\
\hline 41.61 & $\begin{array}{l}\text { 4-(acetylamino) crotonic } \\
\text { acid lactam }\end{array}$ & 0.88 & 49.54 & $\begin{array}{c}\text { 3,6,6-trimethyl -8- } \\
\text { oxabicyclo[5.1.0] oct-2-en-4-one }\end{array}$ & 0.52 \\
\hline 47.71 & piperitenone & 5.29 & 49.95 & $\begin{array}{l}\text { 4,6-dimethyl-2-methyl } \\
\text { pyrimidine }\end{array}$ & 2.18 \\
\hline 48.35 & piperitenone oxide & 25.84 & 51.18 & aromadendren & 0.44 \\
\hline 49.23 & benzene & 0.52 & 54.94 & carvacrol & 4.03 \\
\hline 49.51 & caryophyllene oxide & 1.80 & Total & & 93.22 \\
\hline 54.94 & carvacrol & 1.30 & & & \\
\hline Total & & 90.35 & & & \\
\hline
\end{tabular}

Table 2. Antimicrobial activity (inhibition zones) of the essential oils from M. pulegium and M. spicata L. subsp. tomentosa

\begin{tabular}{|c|c|c|c|}
\hline \multirow{2}{*}{ Microorganisms } & \multicolumn{3}{|c|}{$\begin{array}{l}\text { Inhibition zone (mm) } \\
\text { (Disc diffusion method) }\end{array}$} \\
\hline & M.pulegium & $\begin{array}{l}\text { M. spicata subsp. } \\
\text { tomentosa }\end{array}$ & $\begin{array}{c}\text { Antibiotic } \\
\text { Tobramycin }\end{array}$ \\
\hline Methicillin-resistant Staphylococcus aureus (MRSA) & $12 \pm 1.4$ & $17.5 \pm 0.7$ & $0 \pm 0$ \\
\hline Staphylococcus aureus ATCC 6538 & $16.5 \pm 0.7$ & $11 \pm 1.4$ & $22 \pm 2.8$ \\
\hline Pseudomonas aeruginosa & $12.5 \pm 0.7$ & $21 \pm 8.4$ & $12 \pm 0$ \\
\hline Escherichia coli Q157:H7 & $9 \pm 1.4$ & $20.5 \pm 2.1$ & $20.5 \pm 4.9$ \\
\hline Bacillus cereus CCM99 & $23 \pm 1.4$ & $22.5 \pm 0.7$ & $19 \pm 1.4$ \\
\hline Enterococcus faecium DSM 13590 & $9 \pm 4.2$ & $13 \pm 4.2$ & $12 \pm 2.8$ \\
\hline
\end{tabular}

Note: Results are expressed as mean; \pm standard deviation (SD)

CCM 99 in varying degrees. The biggest inhibition zone $(23$ $\mathrm{mm}$ ) generated from the essential oil was against $B$. cereus and the smallest inhibition zone $(9 \mathrm{~mm})$ was generated against $E$. faecium and E. coli Q157:H7. Morteza-Semnanı et al. (2011) studied that impact of different concentration of the essential oil from M. pulegium was gotten from Mazandaran/Iran. The essential oil generated average $7.7 \mathrm{~mm}$ resistance zone against the E. coli PTCC 1330 and $9 \mathrm{~mm}$ resistance zone against the $S$. aureus end of the study. In this study, it was observed that, for Mentha spicata subsp. tomentosa, essential oil constituted a resistance zone of $22.5 \mathrm{~mm}$ against $B$. cereus at the most while it constituted a resistence zone of $11 \mathrm{~mm} S$. aureus at the least (Table 2).

Essential oil components and antimicrobial effect of $M$. spicata L. subsp. tomentosa and M. pulegium grown under West Anatolian ecological conditions were determined in this study.The difference between our work and the previous studies may be explained by the usage of different methods and different plant collecting periods from different geographical regions and by the different type of bacterial strains used. The observation of an antimicrobial effect against microorganisms shows us that plants containing etheric oils may be used for treatment purposes and may be an alternative to synthetic antibiotics.

\section{Conclusions}

According to the results obtained in this study, it is possible to conclude that antimicrobial activity of the essential oils was slightly lower in comparison to antibiotic (tobramycin) effect on tested six different bacteria genus (MRSA, $S$. aureus, $P$. aeruginosa, E. faecium, E. coli and B. cereus). These findings may be a valuable resource for further food microbiology, biotechnological, and medicinal plants studies. It will also help to understand the importance of the biological diversity and conservation biology efforts.

\section{Acknowledgements}

This research was supported by the TUBITAK 2209-A (Project no: 1919B011500907). 
Morteza-Semnani K, Saeedi M, Akbarzadeh M(2011). Chemical

\section{References}

Başer KHC, Kürkçüoğlu M, Tarımcilar G, Kaynak G (1999). Essential oils of Mentha species from NorthernTurkey. Journal of Essential Oil Research 11:579-588.

Başer KHC, Kürkçüoğlu M, Demirci B, Özek T, Tarımcilar G (2012). Essential oils of Mentha species from Marmara region of Turkey.Journal ofEssential Oil Research 24(3):265-272.

Bayaz M (2014). Essential oils: Antimicrobial, antioxidant and antimutagenic activities. Academic FoodJournal 12(3):45-53.

Chalchat JC, Gorunovic MS, Maksimovic ZA, Petrovic SD (2000). Essential Oil of wild growing Mentha pulegium L. from Yugoslavia. Journal of Essential Oil Research 12:598-600.

Çetin B, Çakmakçı S, Çakmakçı R (2011).The investigation of antimicrobial activity of thyme and oregano essential oils. Turkish Journal of Agriculture and Forestry 35:145-154.

Dastjerdi LS, Mazoji A (2015). Comparative chemical composition of the essential oils of Iranian Achillea oxyodonta from different ecological regions. Journal of Applied Pharmaceutical Science 5(5):106-109.

Deniz L, Serteser A, Kargoğlu M (2010). Local Names and Ethnobotanical Features of Some Plants in Usak University (Uşak) and Its Near Vicinity.AKÜFen BilimleriDergisi 01:57-72.

Ekren S, Yerlikaya O, Tokul HE, Akpınar A,Açu M(2013). Chemical composition, antimicrobial activity and antioxidant capacity of some medicinal and aromatic plant extracts. African Journal of Microbiology Research 7(5):383-388.

Mazandarani M, Mirdeilami SZ, Pessarakli M (2013). Essential oil composition and antibacterial activity of Achillea millefolium $\mathrm{L}$. from different regions in north east of Iran. Journal of Medical Plants Research 7(16):1063-1069.

Mkaddem M, Boussaid M, Fadhel NB (2007).Variability of Volatiles in Tunisian Mentha pulegium L. (Lamiaceae). Journal of Essential Oil Research 19:211-214. composition and antimicrobial activity of the essential oil of Mentha pulegium L. Journal of Essential Oil Bearing Plants 14(2):208-213.

Santos DC, Ribeiro-Santos R, Ventura LAF, Melo NR, Costa BS, Rojas EEG, Salgado NL (2016). Antimicrobial activity studies and characterizatıon of cellulose acetate films containing essential oils. Italian Journal of Food Science 28:248-257.

Sevindik E, Abacı ZT, Yamaner Ç, Ayvaz M (2016). Determination of the chemical composition and antimicrobial activity of the essential oils of Teucrium polium and Achillea millefolium grown under North Anatolian ecological conditions. Biotechnology and Biotechnology Equipment 30(2):375-380.

Stoyanova A, Georgiev E, Kula J, Majda T(2005). Chemical composition of the essential oil of Mentha pulegium L. from Bulgaria. Journal of Essential Oil Research 17:475-476.

Tanker M, Sezik E (1965). A propos de l'huile volatile de Mentha pulegium $L$. var. hirsuta Guss. Journal of Faculty Pharmacy of İstanbul University 1:55-60.

Tommasi L, Negro C, Miceli A(2009). Antimicrobial activity of essential oils from aromatic plants grown in the Mediterranean Area. Journal of Essential Oil Research 21:185-189.

Tucker AO, Naczi RFC (2007). Mentha: An overview of its classification and relationships. In: Mint - The Genus Mentha, medicinal and aromatic plants - Industrial Profiles. Edit BM Lawrence, CRC Press, Boca Raton, FL pp 1-39.

Yasa H, Onar HÇ, Yusufoğlu AS(2012). Chemical composition of the essential oil of Mentha pulegium L. from Bodrum, Turkey. Journal of Essential Oil BearingPlants 15(6):1040-1043.

Yllar M, Kadıoğu İ, Telci İ (2015). Determination of essential oil compositions of some Salvia species naturally growing in Tokat Province. Turkish Journal of Agricultural and Natural Science 2(4):313319. 